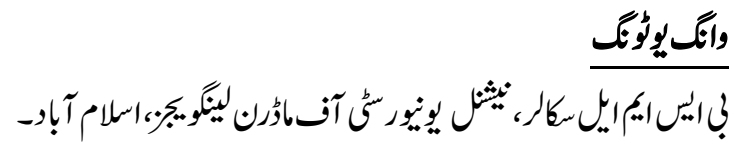

$$
\begin{aligned}
& \text { وأكمارثابيًيم }
\end{aligned}
$$

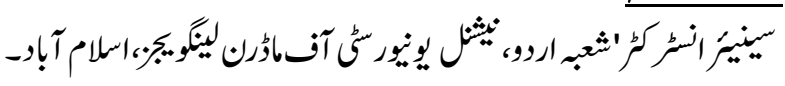

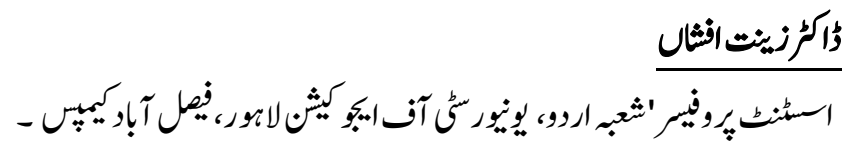

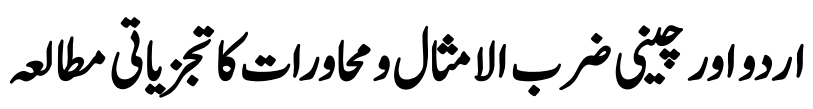

\title{
Wang Yutong
}

BSML Scholar, National Univerrsity of Modern Languages, Islamabad.

\section{Dr. Irshad Begum}

Senior Instructor, Department of Urdu, National Univerrsity of Modern Languages, Islamabad.

\section{Dr. Zeenat Afshan}

Assistant Professor, Department of Urdu, University of Education Lahore, Faisalabad Campus.

\section{Analytical Study of Urdu and Chinese Proverbs and Sayings}

An idiom is an expression or a word or a phrase that has figurative meanings i.e. it is either an expression phrase or a word whose meanings are not visible but hidden, hidden which is traditionally their meaning and can only be understood by locals and is difficult for people of other languages to understand. These idioms or phrases are commonly used in our conversation. If idioms or phrases are translated literally, they do not give the meanings that are meant, the hidden meanings which are metaphorically understood and spoked. Behind every idiom there is an old story, either the locals know that story or they never know what its origin is, how this proverb or idiom started and how it became popular. Until we understand or learn the meaning of these proverbs and idioms that the locals have explained us, we can never guess from the literal meaning of these proverbs what these words mean. This article explains in detail what idiom is 
and its different types. This article explains the meaning of proverbs with examples and analyzes them.

Keywords: China' Paß̧istan' Chinese' Vrdu' Proverb' Idiom' Language' Expression'Meaning.

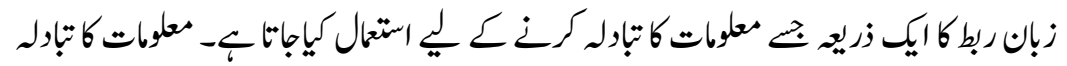

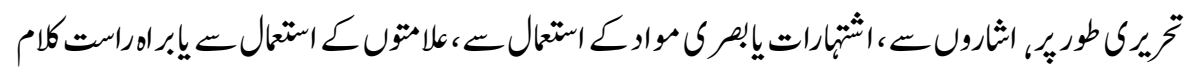

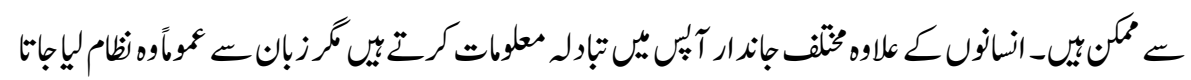

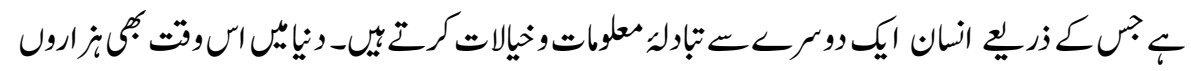

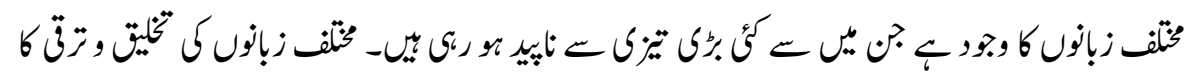

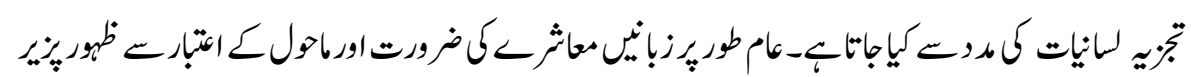

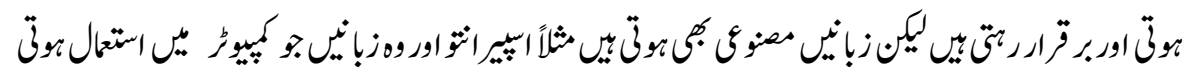

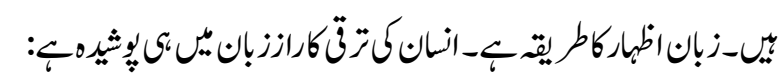

The basic method of human communication, which consists of a structure and words used in the traditional way and is conveyed through speech, writing or gestures. (Lexico, n.d.).

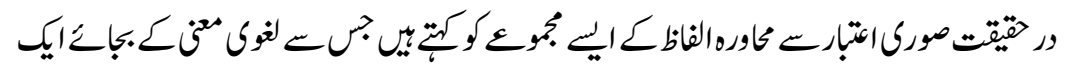

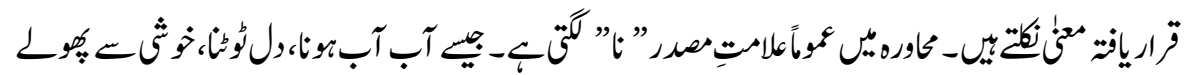

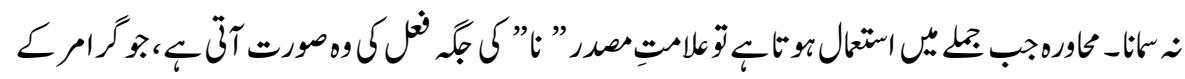

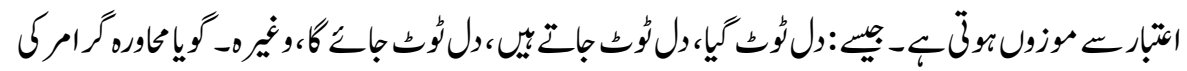

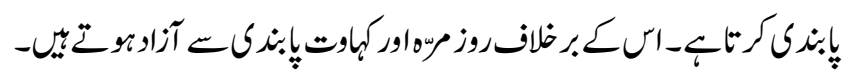

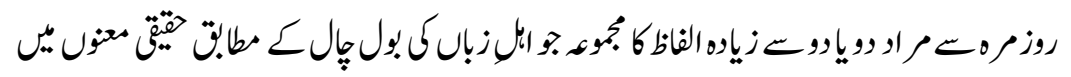

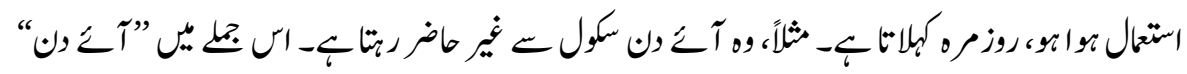

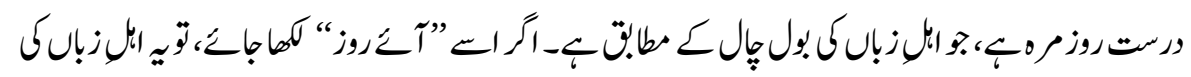

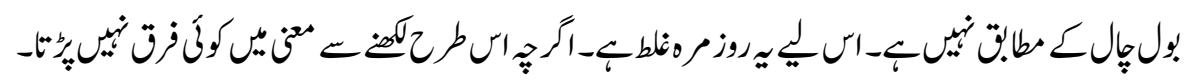




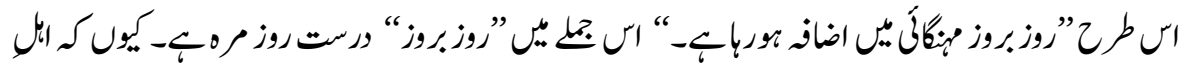

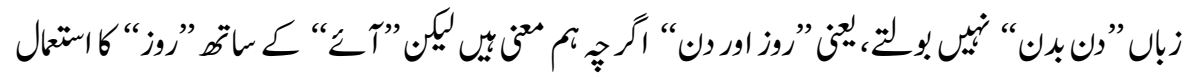

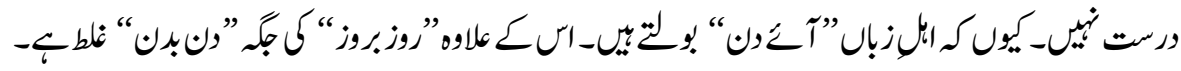

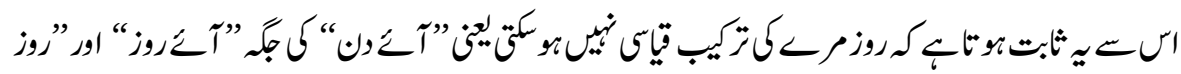

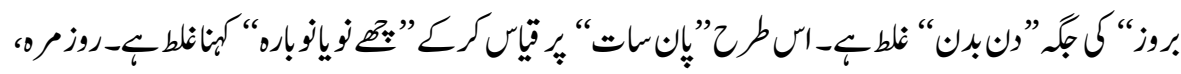

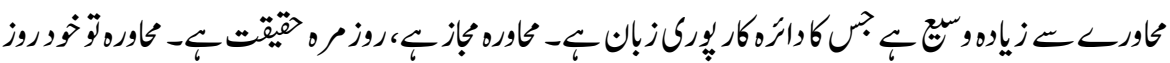

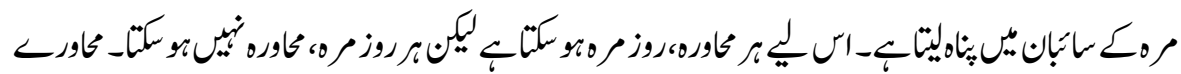

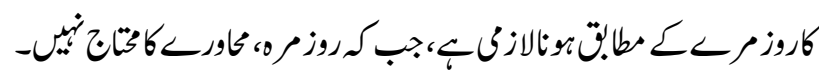

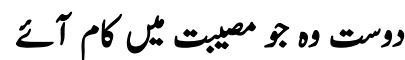

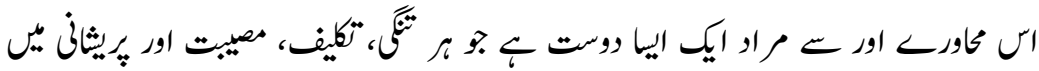

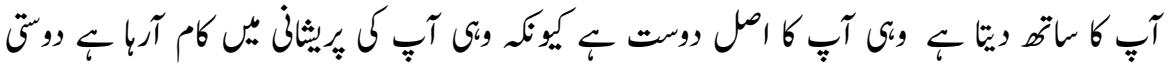

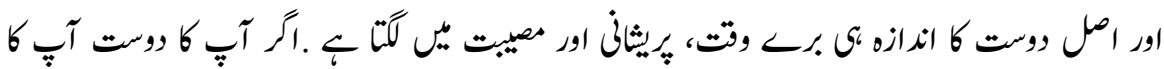

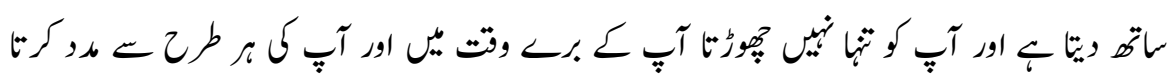

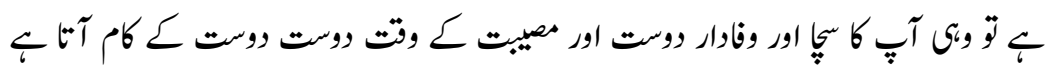
.患难与共

形容人与人之间不管有多少问题都会共同去解 决这个问题，有再多的困难也好，灾难也罢， 都会不离不弃，谁都不会离弃谁，共同去面对 问题解决问题

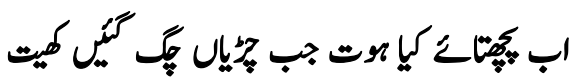

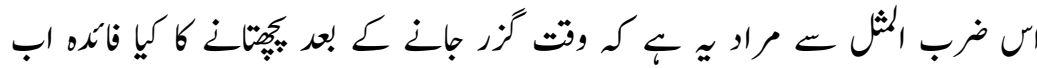

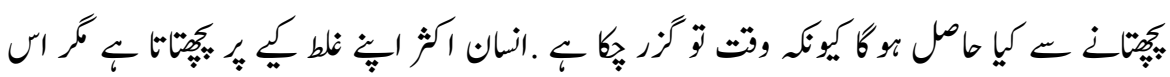

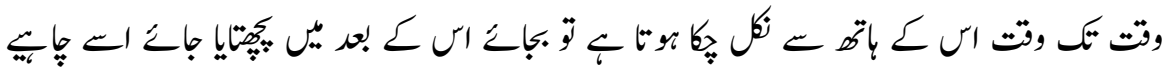

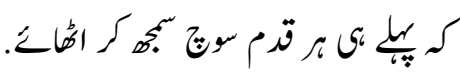




\section{追悔莫及}

形容做事情要三思而后行, 做事情之前要考虑 再三不要盲目, 等到后面如果出现了不可挽回 的局面就为时已晚了, 形容做事情不要让自己 后悔。

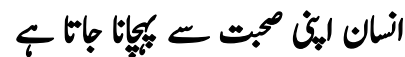

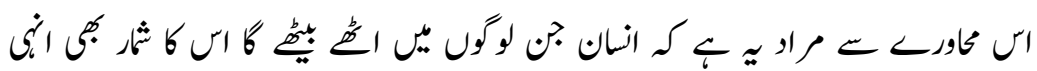

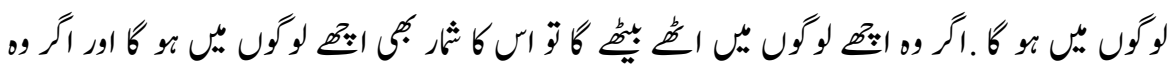

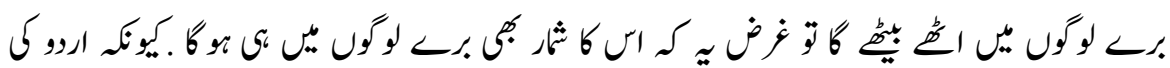

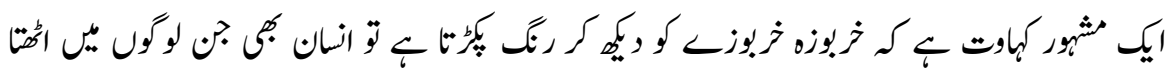

\section{物以类聚}

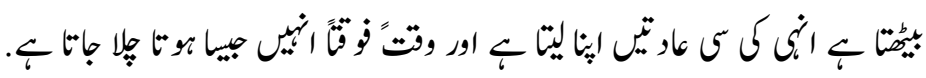

形容物品摆放都是有关联的相同的东西会摆放 在一起, 例如洗衣粉, 香皇, 洗手液都会放在 洗手间里, 调料食材都会放在㷴房。形容人也 是一样的, 你是什么样的人你周围的朋友就大 致是什么样子的人, 通过观察周围的人就能知 道你是一个什么样的人。后来这个词多用于贬 义词用来贬低一个人, 所以通常说物以类聚人 以群分, 是指不好的人在一起会臭味相投, 互 相勾结在一起。

שع كا بول بالا بونا

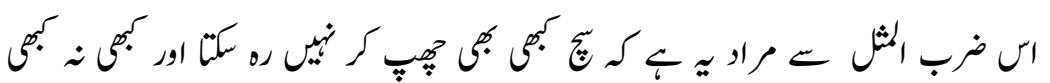

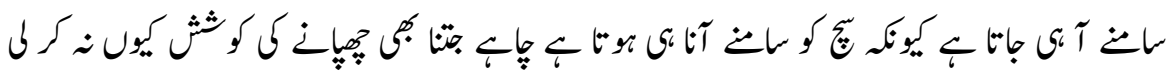

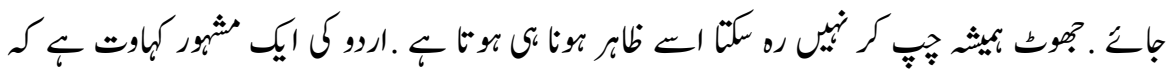

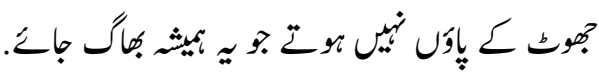




\section{言而有信}

与朋友交, 要言而有信。形容一个人做事情不要高谈阔论 , 说过的话从不兄现承诺, 这样是自毁前程断送了自己之 后的路, 所有的人都不会相信你所说的话, 将很难再去做 什么事情。所以说做什么事情要脚踏实地, 一言既出驱马 难追, 说到就要做到。

\section{كمركبيدى نكأوماح}

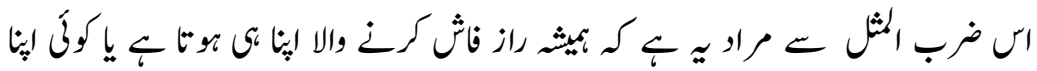

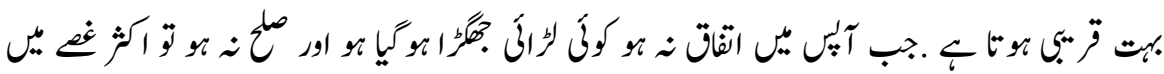

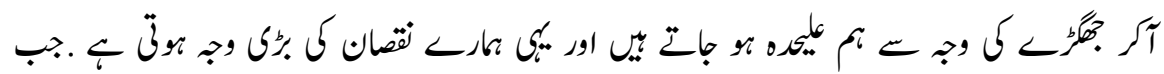

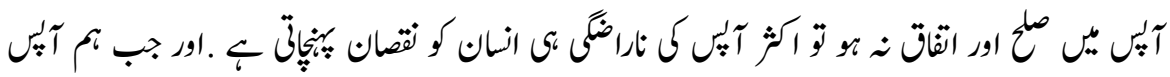

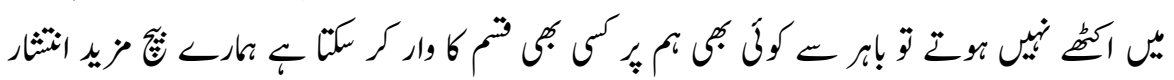

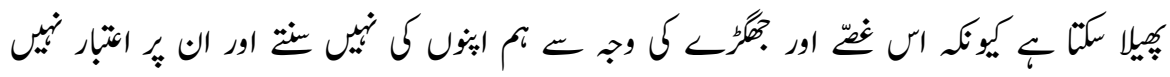

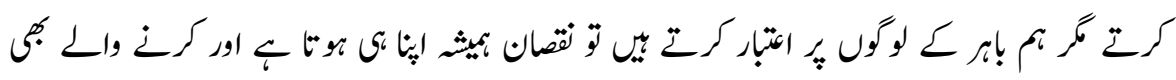

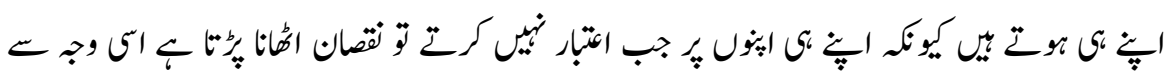

\section{家丑外扬}

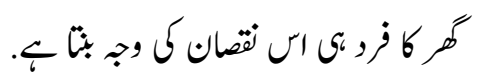

形容家丑是家里的丑事, 不体面、不光彩, 自 然不会愿意将家丑告诉他人或对外曝光。另外 “家丑外扬”会招致外界非议、奸人所乘、矛盾 激化, 从而损毁家庭声誉、破坏家庭和谐。家 丑也可以说称为家事, 家事只要自己的人知道 就可以了, 不必要大肆的宣扬出去让周围的人 都知道, 这样对你自己是没有什么好处的 


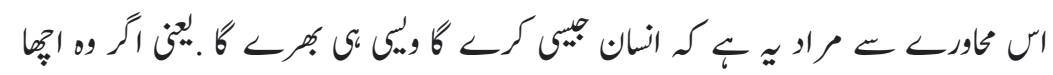

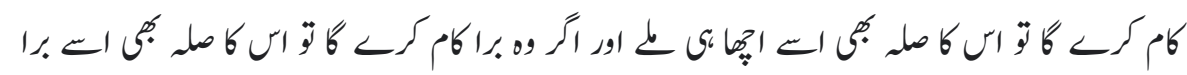

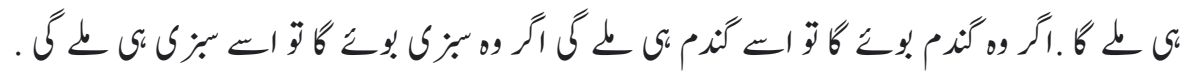

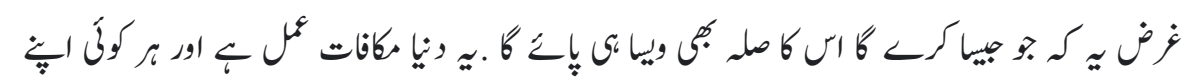

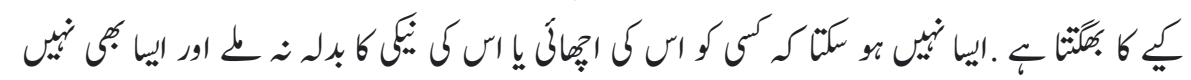

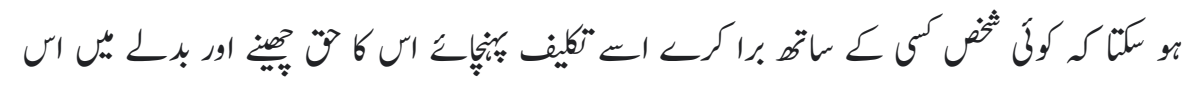

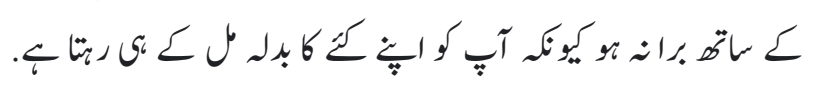

因果报应

这个词之前出自佛教用语。说今生种什么因, 来生结什么果, 善有善报, 恶有恶报。通常用 来形容人要多行善事, 帮助别人后如果日后你 需要帮助那别人也会很乐意帮助你, 如果只行 恶事日后必会受到惩罚。做什么样的事就会得 到什么, 所以也有种瓜得瓜种豆得豆的来源。

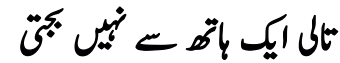

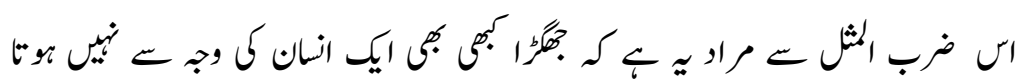

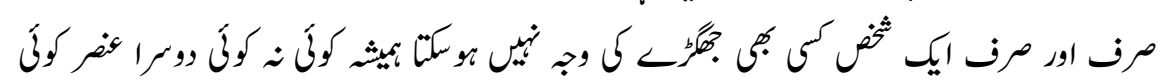

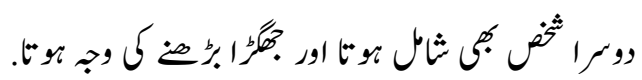

孤掌难鸣

形容做什么事情有的时候还是需要去寻求他人 的帮助做事情才能事半功倍, 例如以一件事情 哪怕不需要他人的帮助也可以完成但时间可能 要半年才能完成, 有了他人的帮助一个星期就 可以完成, 形容做事情还是团队的力量比较强 
大, 一个人的力量取得成功还是比较小的, 就 像一个巴掌拍不响, 力量孤单难以成事。

\section{,}

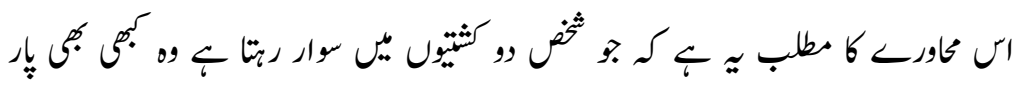

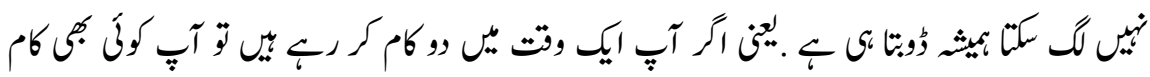

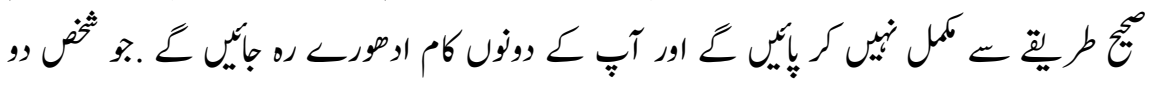

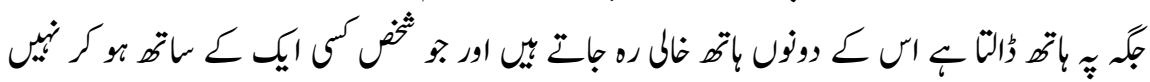

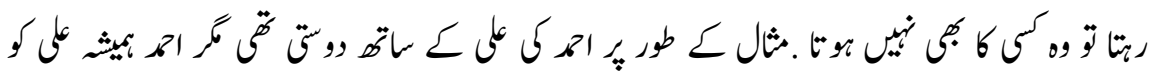

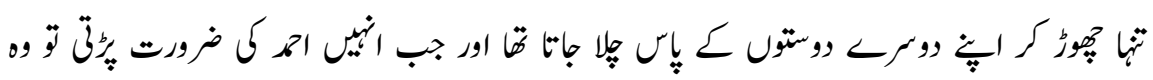

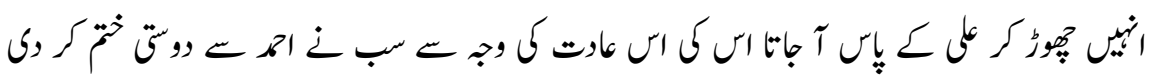
اور امـ كاكوكَ ووست نح ربله

\section{三心二意}

三心是指三种心识, 即真我心识, 阳我心识, 阴我心识; 二意是指两种意识, 即阳意识 (潜 意识）, 和阴意识（显意识）。现代多用于指 一件事情意志不坚定, 犹豫不决, 也指做一件 事情没做好心理还在计划着另一件事, 又想这 样又想那样, 心意不专, 没有一定的操守, 常 指不安心, 不专一。

\section{لاتّل كجوت إقول كنين امنت}

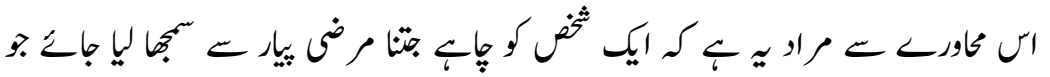

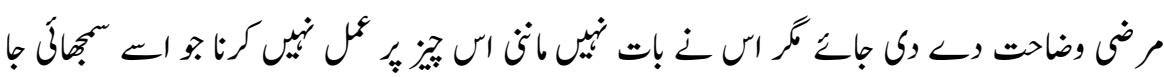

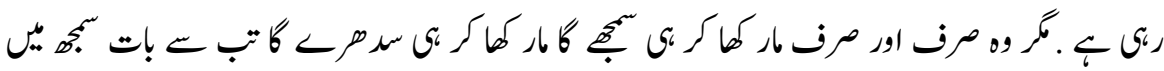

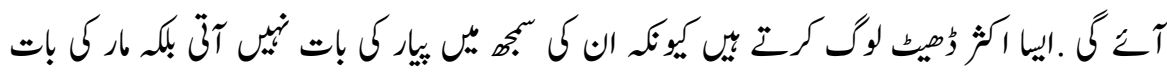

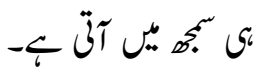


拖泥带水

形容在泥泞道路上行走的状貌, 就像走路拖拖 拉拉的拖着泥带着水。通常比喻办事拖沓不爽 快或语言不简明扼要, 做事情很慢, 磨磨唧唧 的, 说话做事不干净利索。

آبـ

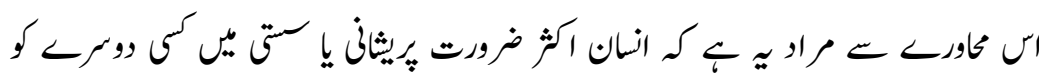

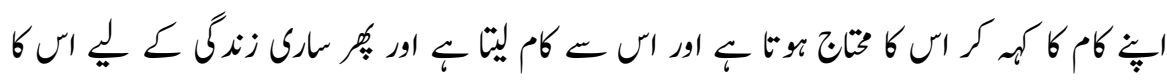

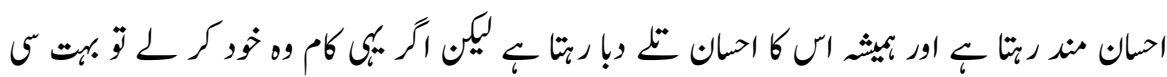

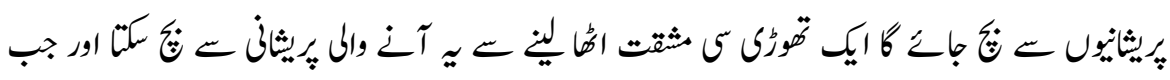

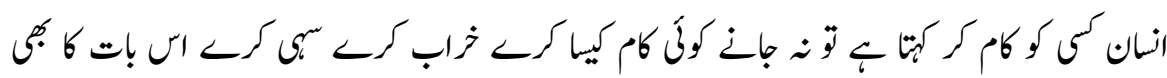

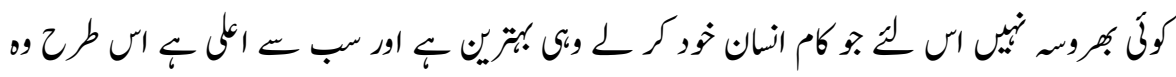

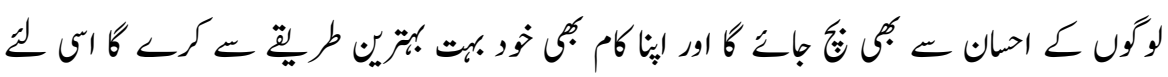

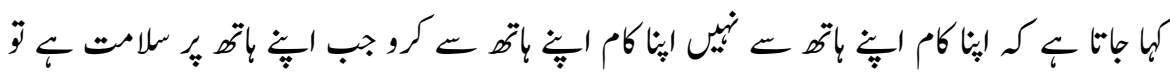

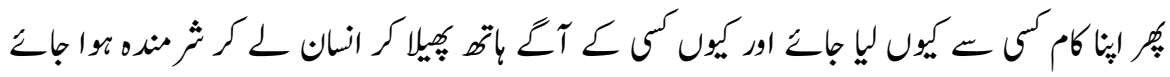
自食其力

形容一个人做事情不能总是依赖他人，要依靠 自己的能力而活而不是总把希望和结果寄托在 他人身上, 要依靠自己的智慧和劳动来获得想 要的结果。

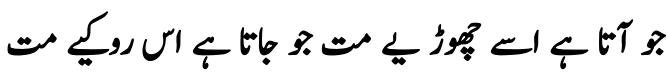

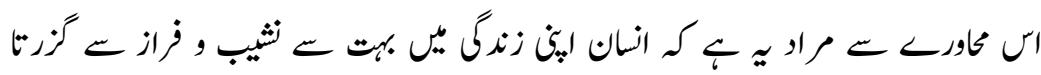

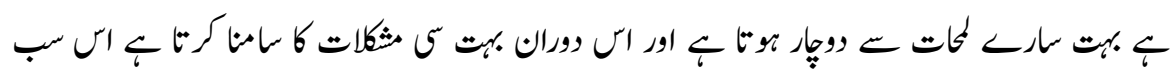

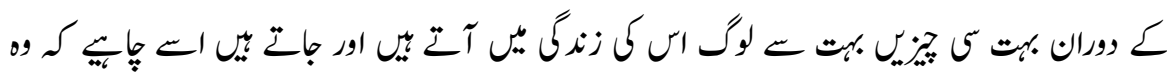

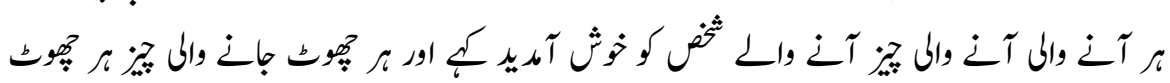




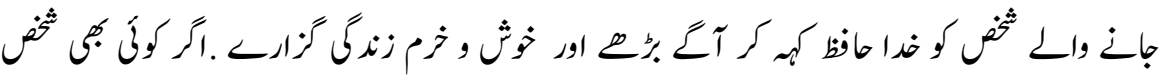

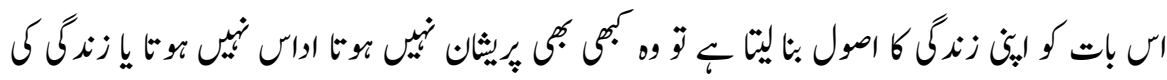

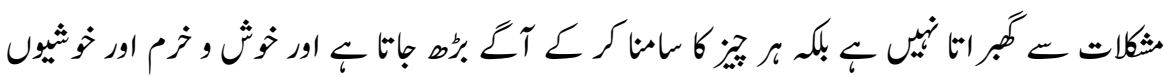

顺其自然

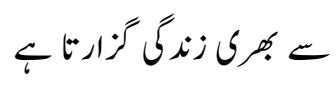

顺就是顺从, 服从, 自然是指应有的结果, 没 有外力使其改变。形容有的事情不能急于求成 , 尽力做好该做的事情, 其结果还得遵从自然 规律。就像春生、夏长、秋收、冬藏这是植物 界的规则, 这也是事物发展的潜在规则。这就 不是指听之任之, 而是主动去发现和利用规律 。就好比人大自然巧, 树大自然直。强扭的瓜 不甜。

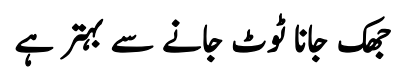

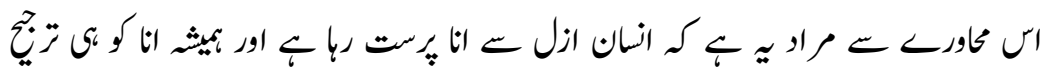

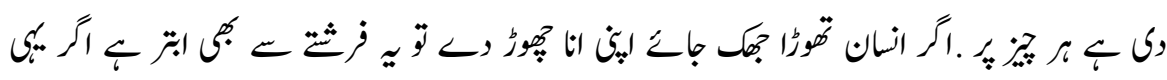

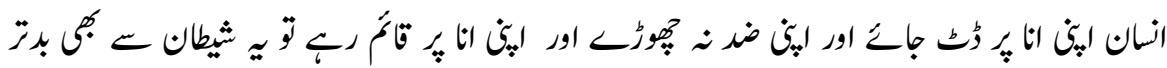

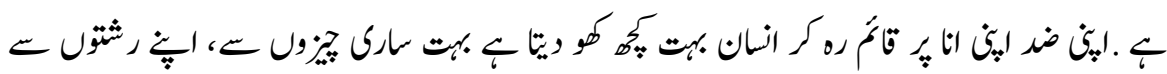

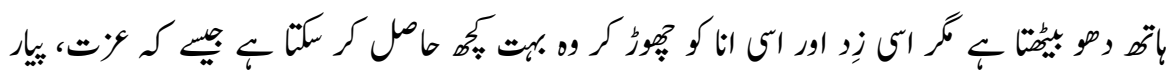

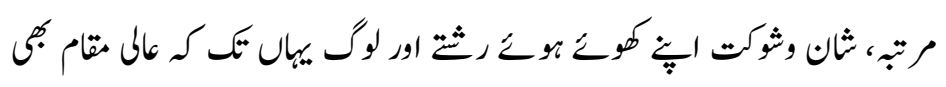

\section{忍气吞声}

形容有的人做事情, 有话不敢言, 有理不敢讲 , 受了欺负也不敢言语勉强忍耐。往往是指被 误解的情况之后, 因为一些因素不敢把真相表 明, 没有办法, 有办法但也无可奈何。 


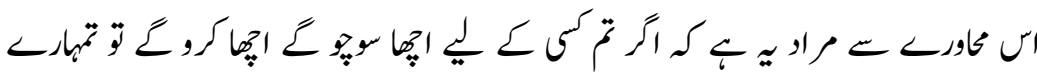

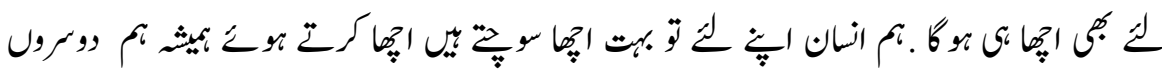

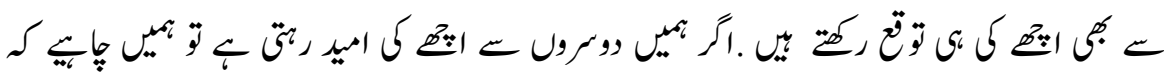

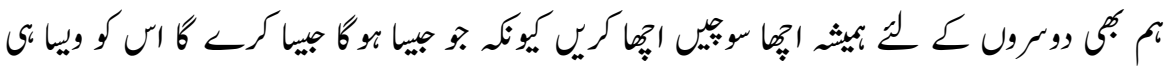

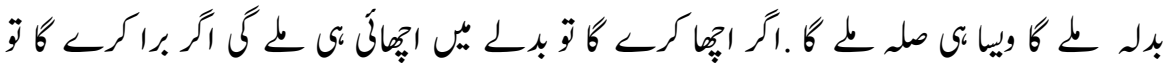

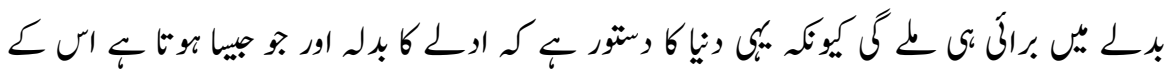

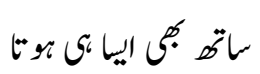

投桃报李

原指朋友之间互送东西, 现代形容人之间做事 情要礼尚往来, 要知恩知德, 滴水之恩当涌泉 相报，他人送我桃子，我将会还人李子。

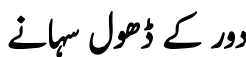

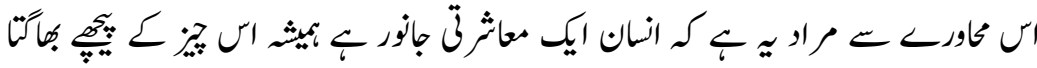

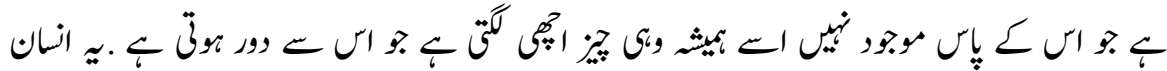

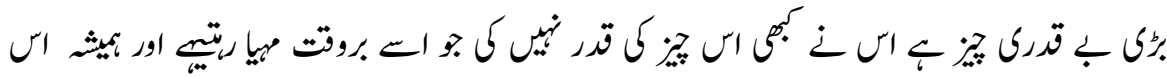

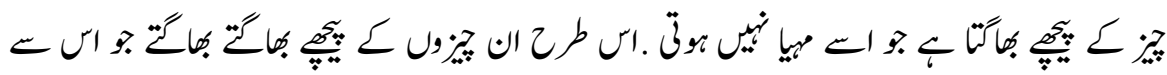

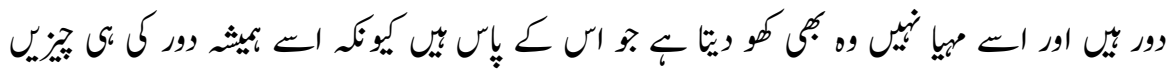

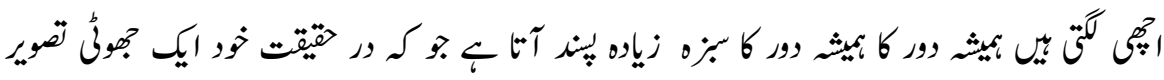

\section{知易行难}

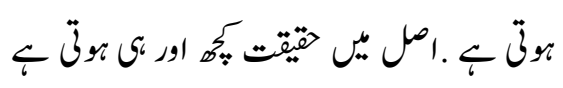

形容有些事情表面看起来很简单, 但实际操作 起来却难于登天。明白认知事物的规律道理是 一回事，能够做到做好是另外一回事。 


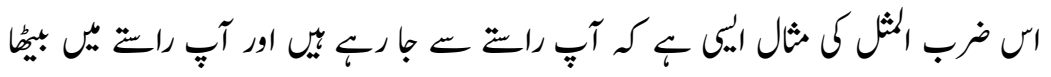

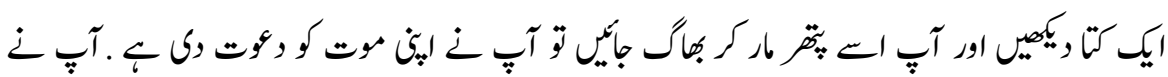

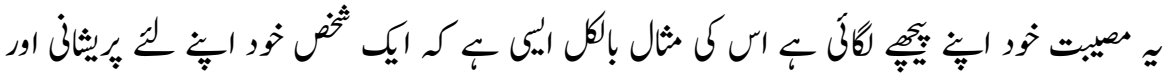

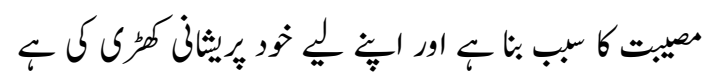

\section{无事生非}

形容一个人做事情总是喜欢把小的事情扩大化 , 把没有的事情要闹到不可挽回的地步。无缘 无故的找纰漏, 故意给别人制造一些麻烦。后 来也用作比喻挑拨两人之间的关系, 把一些别 人的私事告诉其他人，使其发生矛盾。

آسان س كراكمور ميل انكا

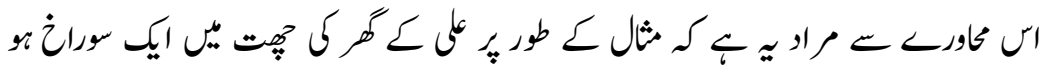

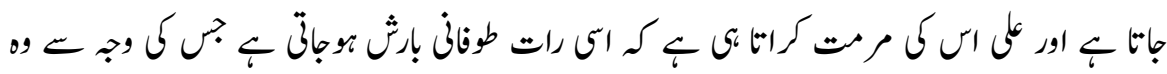

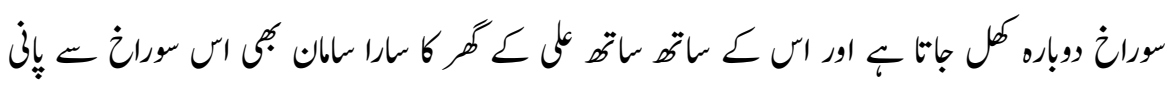

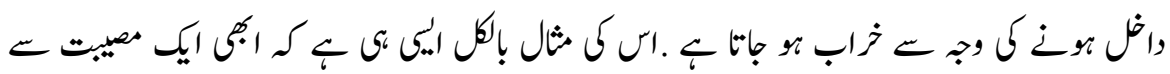

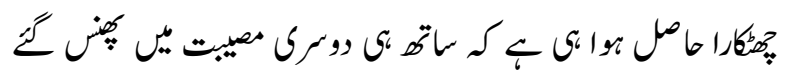

\section{一波三折}

波：指书法中的捺; 折：指写字时转笔锋。原 指写字的笔法曲折多变, 曲折的经历就像写书 法一样一波三折, 运笔过程中要三次转换用力 方向现比喻文章的结构起伏曲折。比喻事情进 行曲折多变, 很不顺利, 也比喻事情进行中意 外的变化很多。 


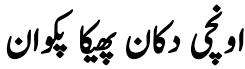

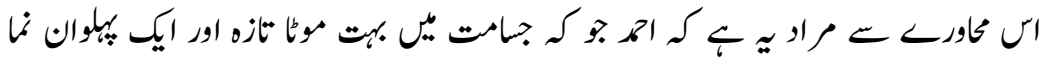

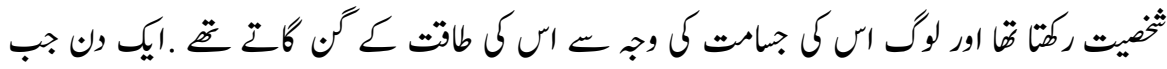

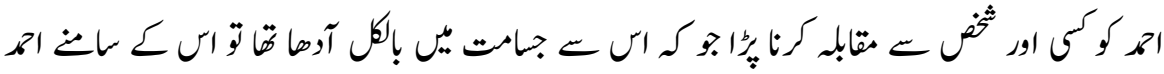

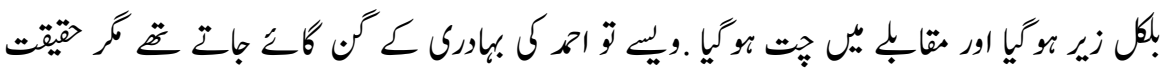

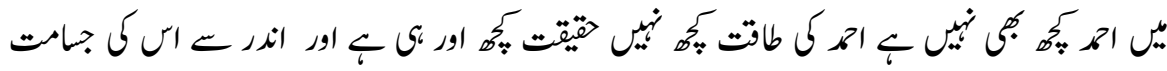

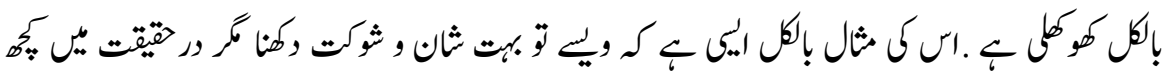

$$
\text { نج }
$$

纸上谈兵

纸上谈兵成语意思纸上谈兵释义: 来代指空谈 不能成为现实, 在纸面上谈论打仗, 谈论用兵 打仗策略。就像做事情不付出实际行动只会一 味的高谈阔论, 讲大道理, 比喻空谈理论不联 系实际情况，不能解决实际问题。

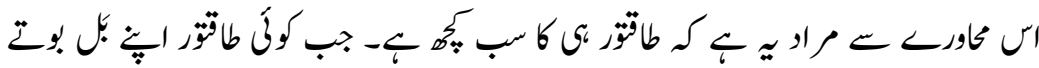

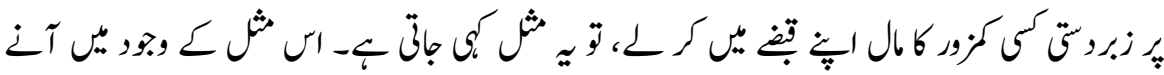

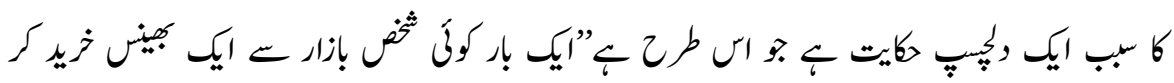

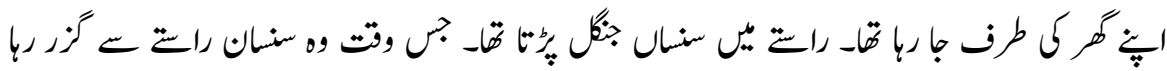

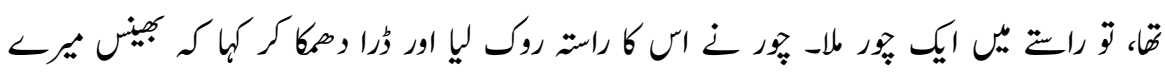

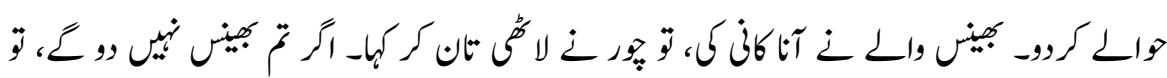

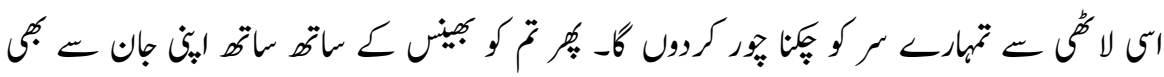

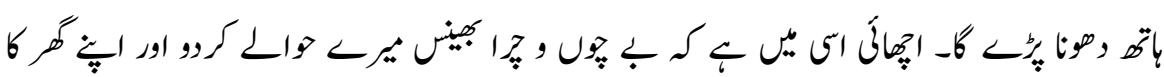

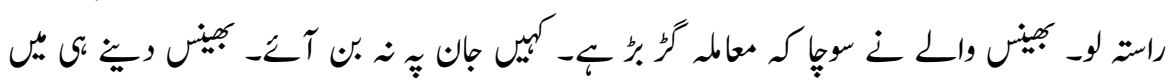




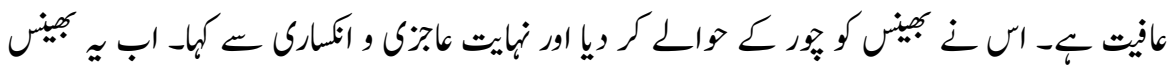

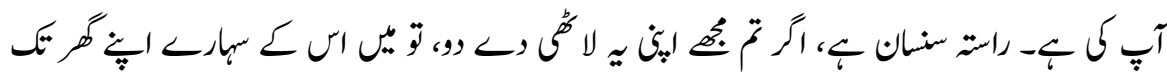

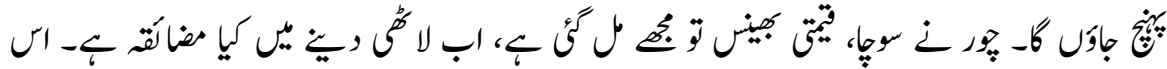

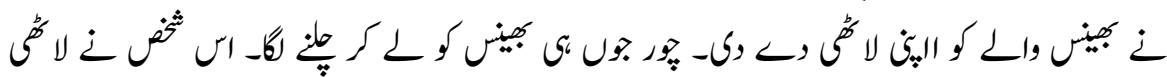

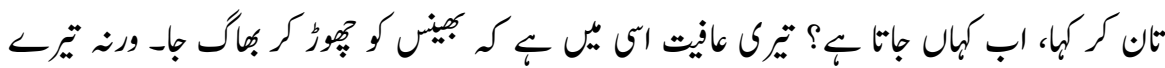

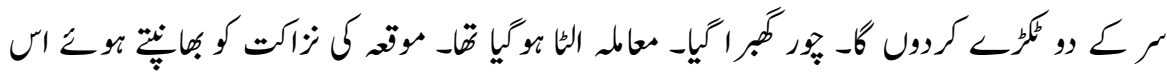

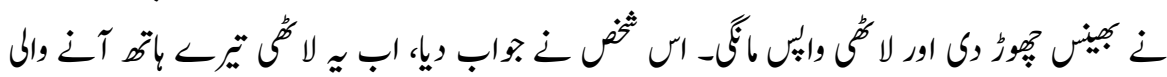

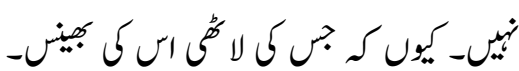

阿舆奉承

阿鱽: 迎合别人的意思, 用言语恭维别人, 说 话做事迎合别人的心意, 竭力向人讨好, 谄媚 , 巴结, 奉承, 溜须拍马, 讨好别人的人。现 代多用于工作中不懂得努力工作出人头地反而 会去讨好老板以达到升职加薪的目的, 在人面 前一味迎合别人，竭力向人讨好。

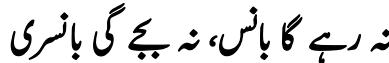

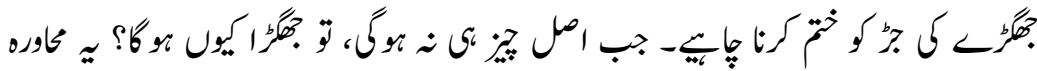

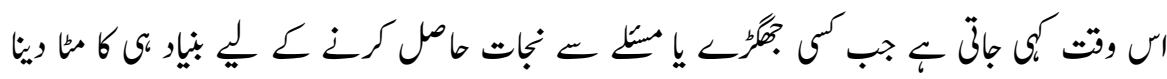

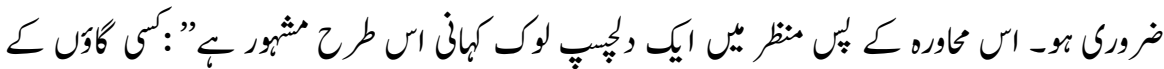

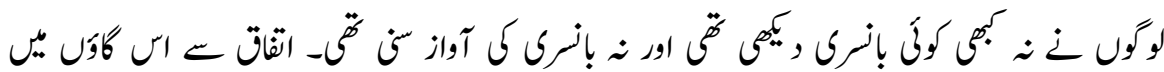

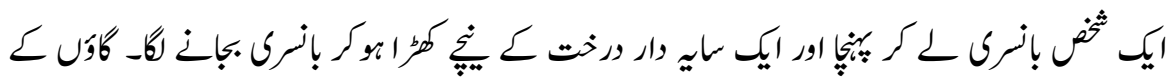

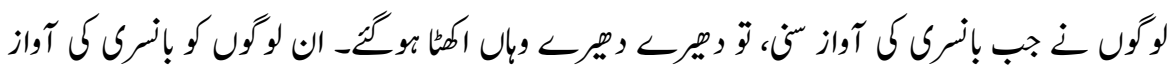

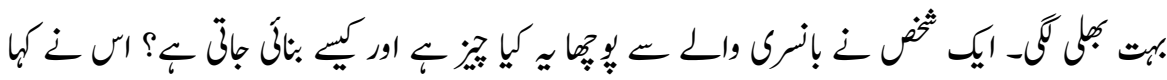

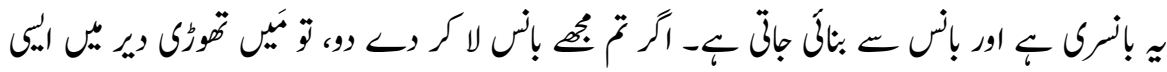

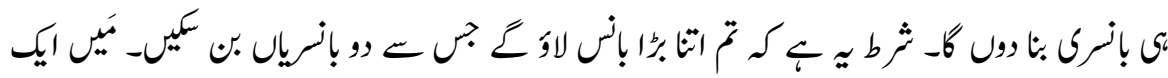




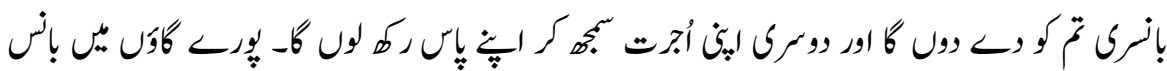

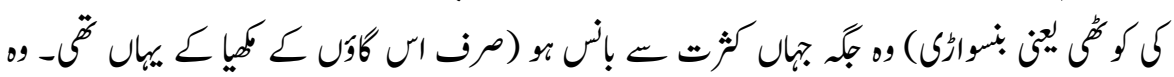

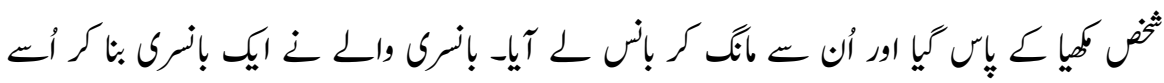

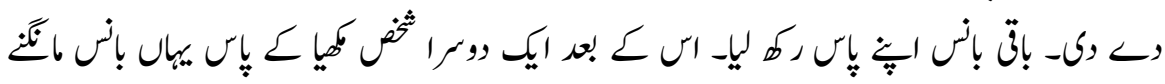

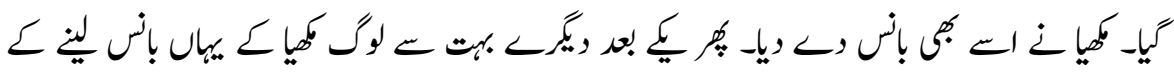

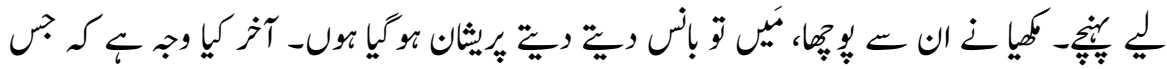

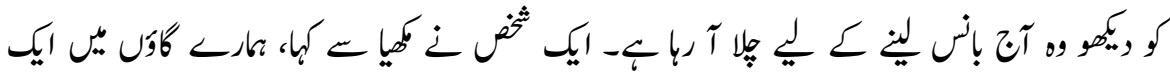

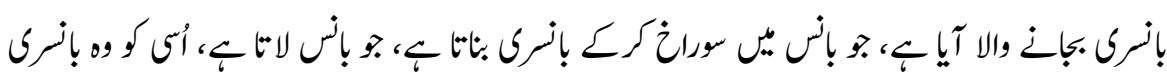

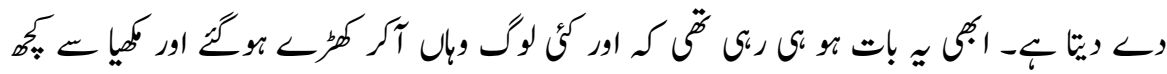

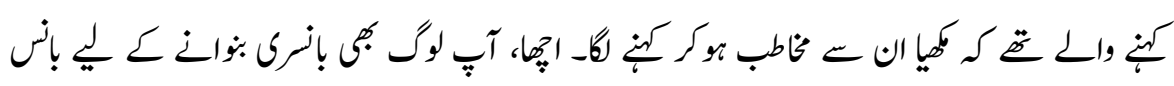

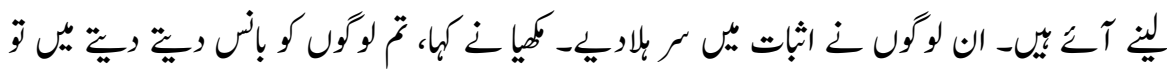

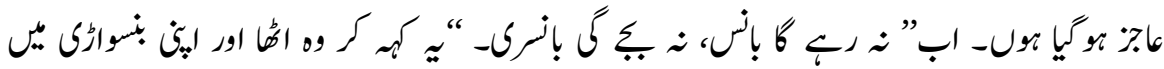

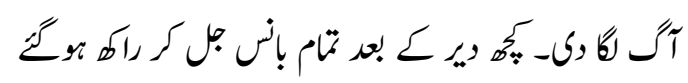

\section{抽薪止沸}

薪代指柴草, 沸代指沸腾。原始用来比喻抽掉 锅底下的柴火, 使锅里的水不在翻滚。形容发 生一件有争议的事情并且闹得沸沸扬扬, 事情 最好的解决办法就是去掉使事情发酵的源头, 使局面不再扩大化，从根本上解决问题。

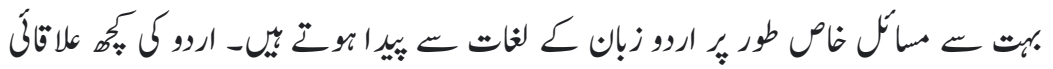

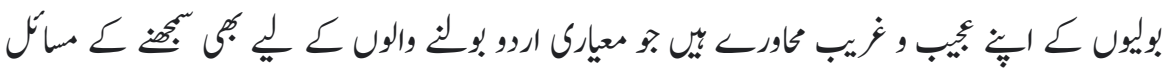

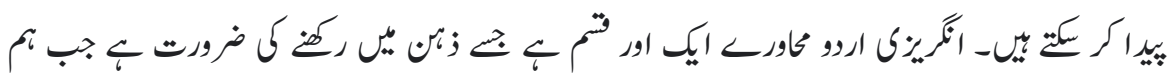

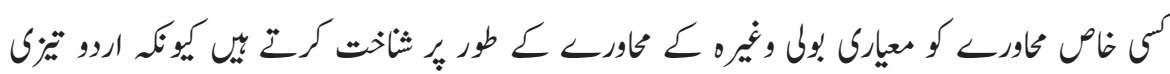

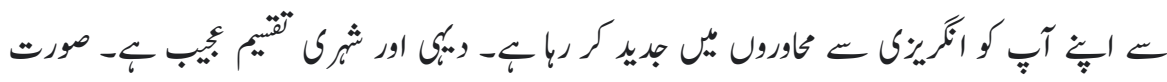




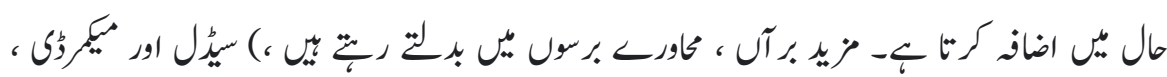

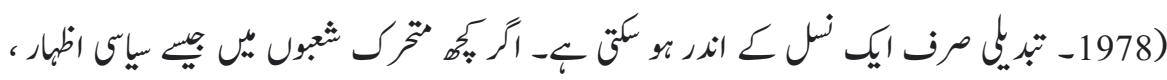

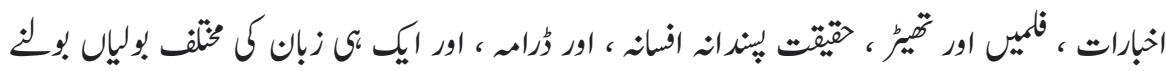

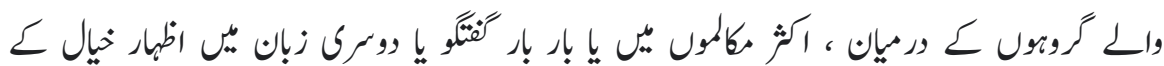

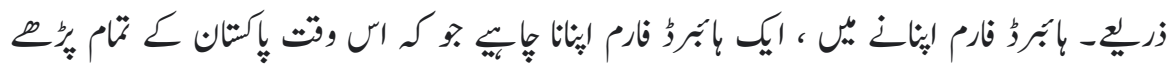

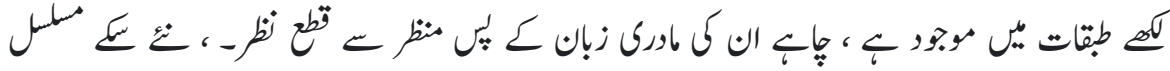

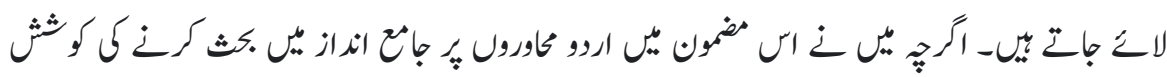

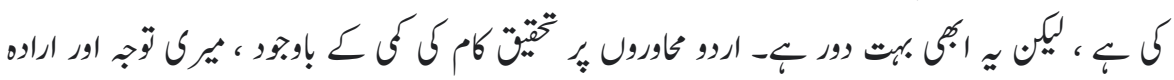

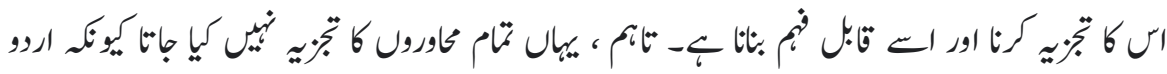

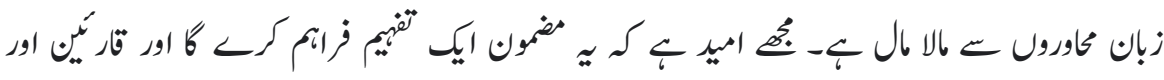

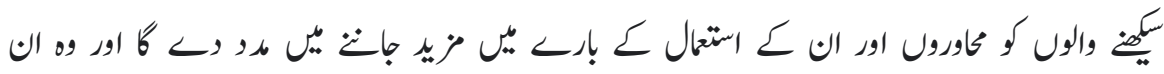

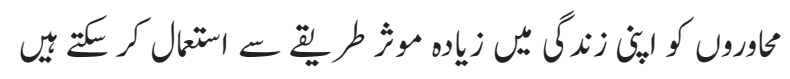

\section{References}

Devices, L. (n.d.). Literary Devices. Retrieved from https:// literarydevices.net/:

https:// literarydevices.net/colloquialism/

Lexico. (n.d.). Retrieved from www.lexico.com: https://www.lexico.com/definition/language

Marian, J. (n.d.). Retrieved from https://jakubmarian.com: https://jakubmarian.com/what-does-idiomatic-mean-whenspeaking-about-language/ 
Qureshi, A. H. (2009, June 6). Retrieved from www.languageinindia.com:

http://www.languageinindia.com/june2009/urduidioms.pdf

Setiawan, A. (2016). Academia. Retrieved from www.academia.edu: https://www.academia.edu/38735700/Situational_setting_affectin g_dialect_shifting_of_non_native_Banjarmasin_Students_of_IAIN Antasari_Banjarmasin?auto=download 